\title{
Informação e conhecimento na era digital
}

\author{
Information and knowledge in the digital age
}

Angela Maria BARRETO'

R E S U M O

Este trabalho propõe uma reflexão sobre a relação sujeito/informação/ conhecimento a partir das mudanças que impuseram à sociedade uma nova configuração, alterando, inclusive, as formas de acesso às informações e de produção de conhecimentos. A discussão aponta para as mudanças atuais ocorridas em todas as esferas da cultura, porém salienta e articula a evolução dos processos comunicacionais e os mecanismos de reprodução do sistema capitalista. Alguns elementos, como o tempo, o espaço e a memória social serão enfatizados, pois além de estarem no cerne das mudanças sociais provocadas pelo aparecimento das tecnologias de informação e comunicação, também são essenciais para a produção de sentidos, requerida para o ato de conhecer. Ao final da discussão, observa-se que a integração das mentes nas redes computacionais ainda não existe num tempo suficiente para que seus efeitos sobre a cultura possam ser devidamente dimensionados. Reconhece-se, contudo, que as redes podem ajudar em certas fases da produção do conhecimento, em especial na da coleta dos dados, pois sua velocidade agiliza esta etapa. Alerta-se, entretanto, para o fato de que a busca inicial requerida para a problematização do conhecimento, surge de perguntas e de significações dadas às respostas encontradas, as quais só ocorrem no sujeito.

Palavras-chave: informação, conhecimento, sociedade da informação, tecnologias de informação e comunicação, cultura.

\section{A B S T R A C T}

The text proposes a reflection about the relationship man-information-knowledge, since the changes which imposed a new societal configuration, altered even the forms of access to information and the production of knowledge. The discussion

\footnotetext{
${ }^{1}$ Doutora, Escola de Comunicação e Artes, Curso de Ciência da Informação e Documentação, Universidade de São Paulo. Membro do Comitê PROLER Salvador, Docente, Instituto de Ciência da Informação, Universidade Federal da Bahia. Av. Reitor Miguel Calmon, s/n, Campus Universitário do Canela, Canela, 40110-100, Salvador, BA, Brasil. E-mail: <ambar@ufba.br>. Recebido em 22/3/2005 e aceito para publicação em 22/6/2005.
} 
points out to current changes, occurring in all spheres of culture; however, it mostly focuses on the evolution of the communication processes and on the reproduction mechanisms of the capitalist system. Some components like the times, space and social memory will be emphasized, because, besides being at the core of the social changes caused by the emergence of the information and communication technologies, they are also essential to the production of meaning, required in the act of knowing. In conclusion, we argue that the integration of the different minds to the computer nets do not exist yet, in a period of time sufficient enough so that their effects over the culture may be adequately measured. Despite recognizing that the net is useful during certain phases of the knowledge production, mainly at the data acquisition/retrieval process, which may be significantly swifted through the use of the net, this article alerts to the fact that the initial quest, the search required for the construction of knowledge comes from the abilities to question and to assign meanings to the obtained answers, which are only achieved by the human individual.

Key words: information-knowledge, contemporary society, technologies of information and communication, culture.

\section{N T R O D U Ç Ã O}

Em recente trabalho (BARRETO, 2003), que buscou nas práticas tradicionais de leitura elementos atuantes nos processos de construção da significação, são apontadas algumas categorias essenciais ao ato de ler. Uma delas refere-se à questão da leitura como via de acesso à informação, que fundamenta a construção do conhecimento. A categoria incide sobre a relação sujeito/informação, que tem sido alterada devido às mudanças ocorridas na realidade social, fato que requer novas discussões.

Este trabalho, desdobramento daquele acima referido, estende a discussão aos debates atuais sobre as novas formas de acesso à informação e de produção do conhecimento. Alguns elementos como o tempo, o espaço e a memória social serão enfatizados, pois além de estarem no cerne das mudanças sociais provocadas pelo aparecimento das tecnologias de informação e comunicação, também são essenciais para a produção de sentidos, requerida para o ato de conhecer.

\section{INFORM AÇÃ O E CONHECIMENTO}

Os termos informação e conhecimento guardam proximidade entre si, mas há uma diferenciação de conceitos entre eles, ainda que não se possa delimitar suas fronteiras. Barreto (1998), cientista da informação conceitua as informações como "estruturas significantes com a competência de gerar conhecimento no indivíduo, em seu grupo ou sociedade". Observa-se que o conceito de informação está atrelado ao da significação que, por sua vez, articula-se à representação do pensamento e à formação da cultura.

Geertz (2001) fala da cultura como processo de produção de sentidos, o espaço/tempo em que os homens vão tecendo as teias de significados a partir de suas interações cotidianas e esboçando uma espécie de mapa para a organização social. Assim, a cultura pode ser entendida como estrutura de significações, como conjunto de textos produzidos, lidos e interpretados pelos atores sociais.

A cultura é, pois, o universo da significação que nasce da interação social, das perguntas, dos diálogos e da capacidade de contar histórias. Segundo Lèvy (2001) o universo da significação é movido por estas três capacidades: a de fazer perguntas leva a espécie humana a ter consciência da sua limitação; a de contar histórias aponta para uma percepção do tempo e para uma organização do 
pensamento; a do diálogo permite ao sujeito trocar experiências e participar da interioridade do outro.

Os homens, ao produzirem as teias de significações para si mesmos, empregam meios técnicos/suportes materiais para transmitir as formas simbólicas, fundamentando, assim, sua vida social nos aspectos da produção, armazenamento e circulação da informação e do conteúdo simbólico. Thompson (1998), ao inserir esta compreensão em sua discussão sobre a mídia e a modernidade, diz que os meios técnicos da informação apresentam certas características gerais, comuns a todos os tempos: a fixação, a reprodução e o distanciamento temporal. O grau de fixação depende do meio utilizado e liga-se aos mecanismos de armazenamento da informação. O atributo da reprodução refere-se à possibilidade de multiplicação de formas e conteúdos simbólicos. A terceira característica, o distanciamento espaço/temporal, significa o afastamento da forma simbólica de seu contexto de produção no tempo e no espaço. Alterações nestas características redundam nas mudanças de cultura. Olson (1997, p.61) refere-se às mudanças históricas, salientando o que chamou de revoluções culturais notáveis:

Duas das revoluções culturais mais notáveis, e seguramente das mais estudadas, a da Grécia clássica do V, IV e III séculos a. C. e a da Europa renascentista, que vai aproximadamente dos séculos XII ao XVII da nossa era foram acompanhadas de mudanças drásticas no modo e na extensão com que se leu e escreveu.

Pode-se dizer que todos os meios técnicos que suportam a informação têm uma relação com o espaço e com o tempo da vida social. Atualmente, com o advento dos suportes digitais, decorrentes do desenvolvimento das Tecnologias de Informação e Comunicação (TIC) houve uma disjunção destas dimensões. Ocorre o fenômeno da simultaneidade não espacial-historicamente mediada, que cria novas formas de interação e ação, novos tipos de relacionamentos sociais. São alteradas as formas de acesso e circulação da informação que vão incidir sobre as maneiras de se construir o conhecimento.

Pode-se depreender destas colocações, que há um diálogo entre informação e conhecimento, um ir e vir, um trânsito que passa pelo simples dado bruto - representação de fatos, textos, gráficos, sinais, etc. - e que se transforma em informação quando processado para utilização. Somente depois de analisada e avaliada em sua relevância e confiabilidade, a informação é, ou não, apropriada pela experiência do sujeito ou grupo, momento em que se pode falar de conhecimento. Ocorre o aprendizado quando o conhecimento se modifica a partir da interação com o ambiente (MORESI, 2000).

O cognitivismo vai tratar o ato de conhecer em seus aspectos mais amplos: os dos processos mentais nele envolvidos. Trata-se de corrente da psicologia que se opõe ao behaviorismo, pois este se ocupou do comportamento e se desobrigou de pensar em processos mentais como percepção, decisão, processamento da informação, compreensão ou significação.

Muitos são os estudiosos que comungam dessa visão. Convém mencionar Piaget, Vygotsky e Bruner, destacando as contribuições dos dois últimos, que enfatizam o papel da linguagem na construção de significados. A contribuição de Vigotsky é fundamental para a compreensão da produção dos significados, pois mostra que a internalização de instrumentos e signos dá-se pela interação social, constituindo o fundamento para o desenvolvimento das funções mentais superiores. É possível, pois, compreender que "para internalizar signos o ser humano tem que captar os significados já compartilhados socialmente." (MOREIRA, 1999, p.113).

Vygotsky (1991) formula uma teoria da construção do conhecimento pautada no contexto cultural, mediado pela linguagem. Para ele não há como desenvolver a inteligência senão 
pelos processos sociais. Nas postulações de Vygotsky, os processos mentais superiores articulam-se aos processos sociais e estes mesmos processos só são compreendidos por meio do conjunto de signos que fazem a mediação entre eles. Assim, o desenvolvimento cognitivo, em seus processos mentais superiores (pensamento, linguagem, comportamento volitivo) depende da socialização, subentendendo-se que a conversão das relações sociais em funções psicológicas se dá por meio da linguagem, tão somente.

O estudioso não desconsidera o papel da genética, enfatizado por Piaget, na constituição da inteligência, mas lhe confere um papel somente enquanto materialidade, em que os processos cognitivos são efetuados. Ele se interessou mais pelo uso dos sistemas de signos enquanto instrumento de mediação entre homem e meio social e enquanto diferencial entre homem e animal. Instrumentos e signos são construções humanas; portanto, produtos culturais e históricos construídos socialmente, mas que, contudo, se oferecem para a formação da individualidade.

A interação entre o indivíduo e o ambiente social constitui tônica da pesquisa em Vygotsky: a noção de interação social como envolvimento de pessoas que intercambiam experiências, conhecimentos, em termos quantitativos e qualitativos, fundamentando os processos de produção de significados. Neste caso, o papel da linguagem é primordial, pois ela garante o intercâmbio da significação, mediando as relações entre pessoas, flexibilizando o pensamento e ampliando a capacidade conceitual e proposicional de cada indivíduo.

$O$ ato de significação é criado a partir dos encontros que o indivíduo tem com o mundo, mediados por atividades simbólicas. A partir daí, há que entender-se o homem como um ser atuante na cultura e através dela, sendo que para essa atuação será necessário compartilhar os significados e conceitos pertencentes ao acervo cultural de determinada comunidade.
Bruner (1997), com um enfoque prescritivo, deu atenção especial à representação, ou seja, a maneira como o indivíduo, ao se desenvolver, vai adquirindo meios de representar seu contexto social. Após os anos 80 , Bruner expande seus estudos, criando uma teoria da mente baseada nas intenções que o indivíduo revela e no significado que ele produz, ao representar. Sua idéia inicial desloca-se do eixo do processamento da informação, constituído por processos internos ao indivíduo, à compreensão da estrutura e crescimento do conhecimento, pautada no ato de significação e intencionalidade. Segundo ele, o processamento da informação lida com dados bem definidos e torna-se incapaz de lidar com a imprecisão, com a polissemia ou sentidos conotativos e metafóricos.

Para Bruner, as experiências e atos humanos são compartilhados e moldados pelos estados intencionais que só são possíveis graças à participação nos sistemas simbólicos oriundos de determinada cultura, evidenciando que não há separação entre o ato individual e o social. O "si mesmo" é concebido no "nós mesmos".

Mais longe, Bruner compreende que a questão da construção do eu por meio do nós, só vai ocorrer pela troca das experiências que acontecem no cotidiano, no dia-a-dia do mundo empírico. E vai além: percebe que a troca das experiências tem na comunicação, oral ou escrita, seu processo organizador, pois esta possui elementos que funcionam como estruturadores, fornecedores de esquemas que favorecem a construção de uma representação mental do mundo, a caracterização de seu fluxo e a segmentação dos eventos dentro deste mundo, permitindo também a constituição da memória social.

Bruner (1997) postula ainda, que o ato de conhecer se dá por construção, integrando-se à posição filosófica do construtivismo. O indivíduo 
é considerado "agente de uma construção que é sua própria estrutura cognitiva.” (MOREIRA, 1999, p.15).

Morin (2001, p.28) assinala o caráter contextual, global, multidimensional e complexo das informações. Portanto, a informação isolada de um contexto, sem relações entre o todo e suas partes, não faz sentido. O sujeito, entretanto, tem caráter multidimensional, sendo ao mesmo tempo, biológico, psíquico, social, afetivo e racional, o que permite diferentes níveis de informação produzida, acessada e trocada, bem como as diversas maneiras de se estabelecerem as relações com ela. Há, portanto, "um tecido interdependente, interativo e inter-retroativo entre o objeto de conhecimento e seu contexto".

Verifica-se, pela revisão acima, que já se aproximam os conceitos informação e conhecimento, uma vez que as trocas de experiências, permeadas pela comunicação, sugerem difusão da informação e manifestam os sentidos que o sujeito dá ao mundo e às coisas. Segundo Santaella (1997), qualquer ato de informar atrela-se ao significado das coisas, dos fatos, dos acontecimentos, o que fundamenta a cultura.

Do exposto, ressalta-se que a relação sujeito/informação/conhecimento encontra-se no cerne da cultura, é fundamento da sociedade humana.

Por que só agora, então, fala-se em sociedade da informação?

\section{O CONTEXTO DA SOCIEDADE D A I NFOR M A ÇÃ O}

No atual contexto, a nova configuração social em andamento está sendo chamada de Sociedade da Informação, resultante da convergência da base tecnológica que possibilitou a representação da informação em forma digital, da dinâmica da indústria e do crescimento da Internet (TAKAHASHI, 2000).
É preciso destacar muitos aspectos, dentre eles as transformações tecnológicas, organizacionais, geopolíticas, comerciais e financeiras, institucionais, culturais e sociais, para uma melhor compreensão da gênese desta Sociedade da Informação.

Contudo, as alterações nos processos comunicacionais e no cenário econômico mundial serão de interesse maior nesta discussão, já que se articulam e estão ligados, diretamente, ao tema Informação e Conhecimento na era digital.

A reorganização da cultura em torno de novos processos comunicacionais aponta para novas configurações sociais. No momento, para a passagem de uma cultura analógica à digital.

Já se aludiu, acima, ao jogo que se dá entre as trocas de experiências e aos vários processos comunicacionais que puderam ser assim engendrados, transformando a cultura e o sentido de mundo. Viu-se que a cultura tem caráter constitutivo e o homem dela participa e nela se realiza.

No contexto da história da Cultura, vê-se que o acesso à escrita garante a superação das formas de transmissão oral, assim como esta garantiu a superação do mundo concreto, exteriorizado e imediato. A imprensa desenvolve novas formas de acesso ao escrito, difundindo-o e melhorando o acesso às informações. Atualmente, vê-se intensas modificações na esfera da cultura, oriundas dos novos processos comunicacionais que além de acelerarem o acesso às informações, permitem novas formas de trocas de experiências e relacionamentos no mundo dos negócios, da política, do lazer e da própria relação entre pessoas.

\section{A Evolução dos Processos Comunicacionais}

Os processos de comunicação foram alterados, continuamente, a ponto de se poder 
afirmar que a história do homem é a própria história dos seus processos comunicacionais. Os estágios da comunicação humana propiciaram diferentes maneiras de cultura. Pode-se considerar: a sociedade apócrifa, a escrita, a impressa e a digital.

Antes da escrita, o tempo fora guardado pela memória, organizada e garantida pelos grupos. Nas sociedades sem escrita existiram os chamados "homens-memória", ou seja, os próprios guardiões da história objetiva e ideológica, os quais tinham o papel de manter a coesão dos grupos. Eram eles idosos chefes de família, bardos ou sacerdotes (LEROIGOURHAN, 1964, p.66). Nessas sociedades a memória coletiva mantinha-se em três pilares: idade coletiva do grupo, prestígio das famílias dominantes e saber técnico ligado à magia religiosa.

A expansão da escrita decorreu lentamente. Um largo período sucedeu-se, desde os tempos em que Platão alertava para seus males, até a Idade Moderna que permitiu sua reprodução técnica, por meio da imprensa. $A$ escrita e outros registros do pensamento provocaram profundas mudanças na memória coletiva. A primeira mudança, quando tal registro assumiu a forma de inscrição. Forte exemplo é a celebração de acontecimentos por meio de monumentos comemorativos. As vitórias e as lutas podiam ser lembradas por representações figuradas e inscrições. Outra mudança significativa, sem dúvida, refere-se ao documento escrito, que também tinha o caráter de monumento. $\mathrm{O}$ documento escrito aparece com muitas funções, sendo que "uma é o armazenamento de informações que permite comunicar-se através do tempo e espaço." (LE GOFF, 1990, p.433).

Os homens passam a dispor de novas formas de preservar o tempo, a partir de novos suportes de memória, pois,

[...] até o aparecimento da imprensa dificilmente se distinguiu entre a trans- missão oral e a transmissão escrita. A massa do conhecido está mergulhada nas práticas orais e nas técnicas; a área culminante do saber, como um quadro imutável, desde a antigüidade, é fixada no manuscrito para ser aprendida de cor...Com o impresso... não só o leitor é colocado em presença de uma memória coletiva enorme, cuja matéria não é capaz de fixar integralmente, mas é freqüentemente colocado em situação de explorar textos novos. Assistiu-se então à exteriorização progressiva da memória individual, é do exterior que se faz o trabalho de orientação que está escrito no escrito. (LE GOFF, 1990, p.457).

Vê-se que a oralidade criou os ritos e os mitos para a transferência da informação e fixação da memória; a escrita retirou a memória do corpo e a transferiu para um suporte material; o alfabeto universalizou a digitação da escrita e a imprensa reproduziu tecnicamente o alfabeto e as imagens.

Desde o aparecimento da imprensa, a leitura é considerada instrumento dos mais importantes na aquisição das informações, as quais, se forem significadas pelo sujeito e apropriadas para seus diferentes contextos, constituir-se-ão em conhecimento. Leitura ainda é a ação que vai garantir o acesso às informações escritas, em qualquer suporte material nos quais elas se encontrem.

A partir de 1970, a convergência de saberes - microeletrônica, computação e telecomunicações - impulsionou o aparecimento das tecnologias da informação e da comunicação que permitiram a aplicação de conhecimentos para geração de novos conhecimentos e criaram dispositivos de processamento da comunicação/informação, em um ciclo cumulativo entre a inovação e seu uso (CASTELLS, 1999). Obviamente, esta inovação tecnológica não foi uma ocorrência isolada. Vários acontecimentos históricos na área da ciência e da tecnologia a 
engendraram: 1947, o transistor possibilitou o processamento de impulsos elétricos; 1951, a invenção do transistor de junção; 1954, o uso do silício na fabricação de materiais; 1957, o aparecimento do circuito integrado; 1990, os circuitos à base de silício e transformação do processamento e armazenamento de dados centralizados em sistema compartilhado: as redes, o que provoca mudanças não apenas na tecnologia, mas nas interações sociais e organizacionais; e 1995, ocorre a privatização da Internet e, com ela surgem novas formas de comunicação e trocas de experiências.

Surge um novo tipo de sociedade: a Sociedade em Redes, também chamada Sociedade Digital. Surge um novo momento da cultura, que Lèvy (1999) chamou de Cibercultura.

Atualmente, o ciberespaço possibilita a constituição da noosfera, um locus virtual de convergência das idéias, da percepção e da memória (LÈVY, 2001).

Estas alterações sociais provocam revoluções em todas as dimensões da existência.

\section{A Nova Ordem Econômica Mundial}

Segundo ARECO (1989), o mesmo contexto de transformações, oriundas do Renascimento, que impulsionou a hegemonia do escrito sobre outras formas de comunicação, favoreceu a concentração de riqueza que permitiu o investimento original do capitalismo. Este novo sistema econômico, baseado na produção de mercadorias orientada pelo mercado, na propriedade privada, na força de trabalho e no comportamento individualista, dentre outros pilares, teve, inicialmente, uma fase mercantilista. Uma série de inovações técnicas incorporadas ao trabalho marcaram a passagem da produção manufatureira à maquinofatura, ponto de partida da Revolução Industrial. As sociedades com base em ações substituem, a partir daí, as empresas de caráter familiar.
Ao final do século XIX, dá-se o surgimento de oligopólios e monopólios para concentrar os esforços empresariais, assinalando a passagem para a fase monopolista do capitalismo.

Entre as duas grandes guerras mundiais, inicia-se a fase imperialista, caracterizada a partir da internacionalização das empresas, com a presença das grandes multinacionais. O Estado e as Ciências (Economia, Administração, Psicologia etc.) deram aportes substanciais a esta fase. Porém, diversos problemas, como escassez de recursos naturais, aumento de preço de várias matérias primas, questões políticas, lutas sociais, dentre outros, foram assinalando o esgotamento do padrão de acumulação, usado até então, o que fez surgir mudanças técnicas, organizacionais e institucionais, que propiciaram um novo cenário. Pode-se dizer que a nova ordem, integralista, é uma resposta encontrada pelo sistema capitalista para um padrão de acumulação baseado em produção em larga escala, com um uso de matéria e energia que redundaram em graves problemas ambientais (LASTRES, 1999).

Castells (1999, p.67) discute o novo padrão de acumulação, baseado na tecnoeconomia, nos avanços das tecnologias da informação e comunicação, como solução ao esgotamento do padrão econômico anterior. Assim, a informação e o conhecimento se constituíram em recursos para o crescimento econômico. A sociedade encontra-se em uma economia da informação, mas continuam valendo as leis da economia. A mudança se apresenta na forma pela qual se usa a informação, ou seja, a conectividade, o que vai possibilitar novas formas de convívio, de negócios, de comunicação e a diminuição de obstáculos tais como o tempo e o espaço (COHEN, 2002, p.27).

A nova configuração social tem como base as Tecnologias de Informação e Comunicação que têm seu significado atrelado à velocidade, à simultaneidade, ao tempo e ao espaço. O que se pode dizer é que, gradati- 
vamente "a informação torna-se cada vez menos ligada ao objeto físico que a contém" (LEVACOV, 1997), o que redunda, por exemplo, em uma diferente noção de biblioteca: as "bibliotecas sem paredes para livros sem páginas".

\section{AS NOVAS DIMENSÕ E D A RELAÇÃ O SUJEITO/I NFORM A ÇÃ O}

Com o aparecimento da sociedade da informação ocorreram grandes e significativas alterações nos suportes de memória, nas noções de tempo e de espaço, o que se reflete, sobremaneira, na relação sujeito/informação/conhecimento. Barreto (2003) faz algumas reflexões a respeito:

\section{Tempo}

A sociedade pós-moderna, ao trazer uma noção de tempo atrelada à velocidade e à simultaneidade, cria rupturas nas formas do tempo e nas formas anteriores de ser, o que incide no tempo da leitura, no acesso à informação, na maneira de conviver e de construir a significação. Quando se acelera a velocidade, pode-se adiantar o tempo da lógica, porém não se é capaz de influenciar o tempo subjetivo biopsíquico- do sujeito (BOSI, 1995), o qual está implicado na significação. Emoção, imaginação e afeto são aspectos reconhecidos na construção do tempo social e deles a memória se reveste.

Nos novos modos de informar, aparecem ao mesmo tempo, numa mesma tela de computador, vários assuntos - é possível " linkar" -, o que faz com que o tempo da leitura acompanhe a velocidade exigida para as decisões rápidas e imediatistas da vida pós-moderna.

Neste caso, a velocidade, ao invés de ampliar o tempo de leitura, exigido para se ter acesso à informação, o reduz, pois o ato de ler exige a "anulação do tempo cronometrável" (BOSI, 1995). Durante o ato de ler prevalece a articulação entre os tempos subjetivo e objetivo.

Ora, se o tempo para "ruminar" as informações não é o mesmo dos tempos das leituras tradicionais, continua, no entanto, a ser indispensável para a produção de sentidos.

Antes da globalização, experimentava-se um tempo real, parte do mundo empírico, que fixava o sujeito ao seu meio social, perpetuando sua experiência por algumas gerações. Atualmente, experimenta-se o meio social por meio de outras experiências que não as locais. As alterações nos tempos sociais apontam para outros tipos de relações entre sujeitos, outro tipo de cultura, a cibercultura, caracterizada pela rapidez e pela lógica utilitária, a qual exige da leitura o caráter da funcionalidade, da velocidade e da simultaneidade. Percebe-se, assim que

[...] o desenvolvimento das memórias
artificiais e das linguagens expressivas
ao longo da história criaram diferentes
modalidades de recepção inclusive a
do escrito. Por isso, distingue-se hoje
leitura em sentido lato, de leitura em
sentido estrito. No sentido lato, o termo
é sinônimo de recepção, na pers-
pectiva mais ampla que ele possa ter
[...] (PERROTTI, 1991, p.231).

\section{Espaço}

Há uma correspondência entre ler num tempo e ler num espaço, sendo espaço e tempo intrínsecos ao ato de ler. O acesso à informação, via leitura, é feito num determinado espaço físico. Ao mesmo tempo, o ler é articulado com um espaço subjetivo, ou seja, o das estruturas imaginárias do sujeito.

$\mathrm{Na}$ sociedade atual, as mudanças nas relações entre espaço e acesso à informação, alteraram a interação do sujeito com seus espaços externo e interno, objetivo/subjetivo. 
Lê-se sentado frente a uma tela de computador, buscando coordenar os olhos que perscrutam as letras, as mãos que clicam e controlam o fluxo da leitura, a audição que sincroniza o ritmo das informações - o que nem sempre é possível, pois a velocidade do nosso cérebro é limitada e, quanto mais informações disponíveis, mais remota a possibilidade de processálas "em tempo" (PEREIRA, 2002, p.4). Por outro lado, lê-se, escreve-se e conversa-se em "sala de bate-papo", ou seja, no espaço virtual da Internet.

O espaço objetivo, o meio real que envolve o leitor durante a leitura, auxilia não só no conforto do corpo, mas, na maneira como o leitor se deixa envolver pelo texto, criando espaços imaginários. Estamos falando de um espaço intersubjetivo, imaginário, modulado pelas circunstâncias do texto e do leitor, e que também é alterado. Assim, o imaginário presente em qualquer ação criadora, produtora de sentido, também se altera. Espaço real e imaginário articulam-se à memória do sujeito, a qual se expressa como parte da ordenação do seu mundo mental, sendo também maneira própria de modelar o mundo.

As transformações nos processos de acesso à informação incidiram nas noções anteriores de tempo e de espaço, duas dimensões que, entretanto, continuam articuladas à noção da memória social e pessoal.

\section{Memória}

A questão da memória remete à história da cultura, pois é na cultura que se situa o universo das significações.

Na sociedade atual, vê-se que alterações no tempo social têm provocado mudanças na forma do sujeito ser no mundo. Pode-se dizer, que a memória intelectual ganhou dimensões extraordinárias na era digital. Mas, e a memória afetiva, a relacional, que também constitui a memória social? Como ficará disponível para as novas gerações se a própria convivência, se o espaço social de trocas relacionais, também foi alterado, no contexto contemporâneo?

É no convívio que ocorrem as trocas, o compartilhamento de experiências. O compartilhamento é condição da memória. Do convívio, sustenta-se a memória. A memória efetiva-se a partir da evocação de lembranças que são corroboradas por outros, capazes, igualmente, de representá-las; desenvolve-se por laços de convivência. Neste sentido, a família e o trabalho são as formas de convivência que mais se distinguem como corroboradoras de lembranças. A memória trabalha sobre o tempo, porém sobre um tempo experienciado pela cultura. Nela, o tempo passado é reconstruído e revivenciado, o que traz um efeito restaurador ao existir humano, uma vez que permite a ressignificação do sentido existencial, atualizando conteúdos experimentados. A memória costura, tece o passado no presente, compondo tramas e enlaçando-se em novas possibilidades existenciais.

Como a memória, o tempo e o espaço requeridos para acessar informações não são estáticos, mas sim dinâmicos: mudaram as condições, mudaram os pontos de vista, mudaram os interesses do sujeito, mas memória social continua sendo o resultado do convívio, dos entrelaçamentos das experiências de um tempo vivido num determinado espaço.

Neste particular, aponta-se a significação ontológica da memória, a de revelar à pessoa uma maneira peculiar de escolher-se a si própria. É entendida também como a dialética entre o individual e o social. O indivíduo desloca-se do seu mundo individual para o social e deste para aquele. Esse deslocamento permite o contato do ser humano com o mundo. É nessa trajetória que se estabelece o sentido existencial. Ao sair de si e enxergar o outro, o ser humano instaura o espaço sociocultural e, neste espaço, na esfera das relações entre sujeitos, estabelecem-se as significações. Não é possível estabelecer uma memória exclusivamente individual, porque as lembranças pessoais são constituídas pelas 
referências dadas pelo grupo social. O que é individual é apenas a maneira singular pela qual cada indivíduo articula o acervo de lembranças.

De forma semelhante, cada grupo, em cada tempo e espaço, articula de maneira peculiar suas lembranças em quadros sociais que são comuns.

A memória, enquanto acervo de lembranças, não é um produto resultante do acúmulo de vivências, mas um processo que se faz no presente para atender às necessidades do presente. Eis aí outra característica da memória. Esta característica permite sua reconstituição de maneira distinta do fluxo das vivências, o que ocorre a partir da localização espaço/tempo que o grupo define. É neste sentido que o passado não é conservado pela evocação das lembranças, mas reconstruído numa dimensão presente.

As lembranças não podem ser conservadas, apenas evocadas. Somente a evocação conserva a lembrança; portanto, a memória é menos um mecanismo de recepção e armazenamento de experiências e mais um processo dinâmico e interativo que se desenrola no cotidiano do homem social, por meio do processo comunicacional.

Certamente, a trajetória da humanidade vai mostrar que a escrita e, depois o impresso, foram modos de memória que, de alguma forma, criaram um afrouxamento do simbólico, mas que estabeleceram uma relação própria com a produção da significação. O testemunho deixado pela história, leva a acreditar que também a era digital irá reorganizar suas relações sujeito/informação, reorganizando, assim, as formas de sociabilidades em torno dos novos meios de comunicação e garantindo a produção da memória social.

A reorganização da escrita e do impresso, no entanto, foi um processo lento, ao contrário do que ocorre na atualidade, em que a pressa, a velocidade e a simultaneidade são os fundamentos da nova realidade. Com esta nova perspectiva, percebe-se que o tempo do mundo globalizado se distancia do espaço e do tempo local. Sendo assim, "o acervo da informação é uma capitalização que implica na atrofiação da memória" (VIRILIO, 2003).

\section{CONSIDERAÇÕ ES FINAIS}

Podemos iniciar o fechamento destas reflexões a partir não só do que foi dito, mas articulando-o, ainda, às falas de alguns estudiosos da questão.

Torello (2001, p.2) diz que "as inovações determinam mudanças sociais e culturais rápidas que o indivíduo não consegue assimilar e, assim, provocam contínuos desequilíbrios". Desequilíbrios porque não há um tempo suficiente para uma homeostase, para que a sociedade sedimente os novos valores da cultura. As novidades não são devidamente processadas, não há o tempo para relacioná-las às referências éticas, culturais, científicas, filosóficas, enfim, ao universo simbólico, - o que gera a perda dessas referências, isto é, tornam-se obsoletas bem antes de se constituírem guias para o sujeito.

Bosi (1995) fala dos novos tempos, que se propõem a salvaguardar a memória, mostrando que esta proposta, na realidade, enseja uma contradição. A anulação do tempo cronometrável vai incidir sobre a memória social, causando sua perda, pois "a memória, saltando sobre a cronologia, recupera o tempo perdido enquanto anula o passado como passado e o chama para a consciência viva do presente".

Entretanto, a relação com as informações digitalizadas, apresenta-se com um caráter agressivo que substitui a atitude reflexiva, requerida na significação. Neste aspecto, é bom assinalar que a memória digital é universalizante, gerada num espaço e num tempo não experenciados, sem vínculo humano presencial. Trata-se de um vínculo coletivo, virtual, em rede, com informações produzidas por muitos sujeitos, 
distantes uns dos outros, em contextos socioculturais que Ihes dão referências diversas. Mais ainda, sua difusão ocorre de forma desordenada, além de que a memória digital é diferente da memória da significação. Enquanto aquela é universalizante, esta é particularizante, estando ligada à vida dos seres, ao sensível, pois que implica afeto, emoção, vínculos, formas sociais de convívio num ambiente materializado pelos objetos e espaços criados diferenciadamente por cada grupo de pessoas.

Lèvy $(1993,2001)$ tem usado o termo inteligência coletiva para se referir às formas coletivas de conhecimento na era da informatização, que em nada se parecem com os processos coletivos constituídos pelas comunidades científicas até então. Referiu-se a uma consciência coletiva, solidária, formada a partir do compartilhamento de idéias, mas desconsiderou que a produção de fato ocorre num espaço social real em que sujeitos interagem.

Vê-se que a integração das mentes, neste novo nível de relacionamento humano, a noosfera, o locus da nova condição humana,

\section{REFERÊ NCIAS}

ARECO, A.M.B. O fenômeno burocrático nas bibliotecas. 1989. Dissertação (Mestrado em Biblioteconomia) - Pontifícia Universidade Católica de Campinas, Campinas, 1989.

BARRETO, A.A. Eficiência técnica e econômica e a viabilidade de produtos de informação. Disponível em: <http://www.alternex.com.br>. Acesso em: 22 jun.1998.

BARRETO, A.M. Memória de leitura: trajetória de idosos do Vale do Paraíba: contribuição aos estudos das relações entre sujeito/informação e produção de sentidos. 2003. Tese (Doutorado) - Escola de Comunicações e Artes - Universidade de São Paulo, São Paulo, 2003.

BOSI, A. Considerações sobre o tempo e informação. Cidade do Conhecimento. São Paulo: USP, 1995. Disponível em: <http://www.cidade.usp.br/ ainda não existe num tempo suficiente para que seus efeitos sobre a cultura possam ser devidamente dimensionados. Seria imprudente dizer que Lèvy está enganado ao defendê-la. Mesmo assim, algumas considerações já puderam ser estabelecidas nestas discussões.

O produto do conhecimento, fruto de idéias, deve ser documentado na rede e, assim, facilitar o seu acesso a outros sujeitos, mas não devemos esquecer-nos que a rede não permite a produção do conhecimento em si. O conhecimento surge de perguntas sobre as mais variadas situações, o que exige tempo de reflexão por parte do sujeito. O conhecimento é produzido a partir de análises, de interpretações de dados, o que pressupõe a reflexão. A rede pode ajudar numa fase da produção do conhecimento, em especial na da coleta dos dados, pois sua velocidade agiliza esta etapa. Porém, a indagação inicial requerida para a problematização do conhecimento, bem como a busca do significado para as respostas encontradas, só podem ser realizadas pelo sujeito produtor de idéias (BOSI, 1995).

arquivo/artigos/index 0401.php>. Acesso em: 25 mar. 2003.

BRUNER, J. Atos de significação. Porto Alegre: Artes Médicas, 1997.

CASTELLS, M. A Sociedade em rede. São Paulo: Paz e Terra, 1999.

COHEN, M.F. Alguns aspectos da informação na economia da informação. Ciência da Informação, Brasília, v.31, n.3, p.26-36, 2002.

GEERTZ, Clifford. Nova luz sobre a Antropologia. Rio de Janeiro: Jorge Zahar, 2001.

LASTRES, H.M.M. Informação e conhecimento na nova ordem mundial. Ciência da Informação, Brasília, v.28, n.1, 1999.

LE GOFF, J. História e memória. Campinas: Unicamp, 1990. 
LEROI-GOURHAN A. Le geste et la parole. Lisboa: Edições 70, 1981.

LEVACOV, M. Bibliotecas Virtuais: $®$ evolução?. Ciência da Informação, Brasília, v.26, n.2, p.125-135, 1997.

LÈVY, P. Cibercultura. São Paulo: 34, 1999.

LÈVY, P. As Inteligências coletivas. São Paulo: SESC, 2001. Disponível em: <http://www.google. com.br/ sesc.pierre. levy.htm>. Acesso em: 9 abr. 2003.

LÉVY, P. As tecnologias da inteligência: o futuro do pensamento na era da informática. Rio de Janeiro: 34, 1993.

MOREIRA, M.A. Teorias da Aprendizagem. São Paulo: EPU, 1999.

MORESI, E.A.D. Delineando o valor do sistema de informação. Ciência da Informação, Brasília, v.29, n.1, p.14-24, 2000.

MORIN, E. Os sete saberes necessários à educação do futuro. 3. ed. São Paulo: Cortez, 2001.

OLSON, D.R. A Escrita e as revoluções conceituais da Grécia Clássica e da Europa Renascentista. In: O mundo no papel: as implicações conceituais e cognitivas da leitura e da escrita. São Paulo: Ática, 1997. p.61-80.

PEREIRA, T.A.C. Informação e conhecimento. Leopoldianum. Santos, n.77, 2002.

PERROTTI, E. Confinamento cultural, infância e leitura. São Paulo: Summus, 1991.

SANTAELLA, L. Globalização e Multiculturalismo. Anais... AMPAB,1997. p.35-47.

TAKAHASHI, T. (org.). Sociedade da informação no Brasil: Livro Verde. Brasília: MCT, 2000.

THOMPSON, J.B. A mídia e a modernidade: uma teoria social da mídia. 2. ed. Petrópolis: Vozes, 1998.

TORELLO, G. O psiquiatra na Internet, um paradoxo? Psiquiatria na prática médica, Botucatu, jul. 2001. Disponível em: <http://www.unifesp.br/dpsiq/polbr/ ppm/ especial 02.htm>. Acesso em: 9 abr. 2003.

VIRILIO, P. L'Integralismo tecnológico. Enciclopedia multimediale. Disponível em: <http://www.emsf.rai. it/interviste.asp?d=422>. Acesso em: 10 abr. 2003.

VYGOTSKY, L.S. A formação social da mente: o desenvolvimento dos processos psicológicos superiores. 4.ed. São Paulo: Martins Fontes, 1991. 